\title{
Unraveling the development behind unisexual flowers in Cylindropuntia wolfii (Cactaceae)
}

\author{
Niveditha Ramadoss ${ }^{1 *}$, Amy Orduño-Baez ${ }^{1,2}$, Carlos Portillo ${ }^{1}$, Scarlet Steele ${ }^{1}$, Jon Rebman ${ }^{3}$ and \\ Lluvia Flores-Rentería' (1)
}

\begin{abstract}
Background: In certain unisexual flowers, non-functional sexual organs remain vestigial and unisexuality can be overlooked leading to the ambiguous description of the sexual systems. Therefore, to accurately describe the sexual system, detailed morphological and developmental analyses along with experimental crosses must be performed. Cylindropuntia wolfii is a rare cactus endemic to the Sonoran Desert in southern California and northern Baja California that was described as gynodioecious by morphological analysis. The aims of our project include accurately identifying the sexual system of C. wolfii using histological and functional studies and characterizing the developmental mechanisms that underlie its floral development.
\end{abstract}

Methods: Histological analyses were carried out on different stages of C. wolfii flowers and controlled crosses were performed in the field.

Result: Our results identified C. wolfii to be functionally dioecious. The ovule and anther development differed between staminate and pistillate flowers. In vivo pollen germination tests showed that the pollen of staminate and pistillate flowers were viable and the stigma and style of both staminate and pistillate flowers were receptive. This suggests that there are no genetic or developmental barriers in the earlier stages of pollen recognition and pollen germination.

Conclusions: Despite being functionally dioecious, we observed that functionally pistillate individuals produced fruits with a large number of aborted seeds. This implies that not only does this species have low reproductive success, but its small population sizes may lead to low genetic diversity.

Keywords: Dioecy, Cylindropuntia wolfi, Pollen viability, Unisexual floral development

\section{Background}

The breeding or sexual systems of organisms is a critical aspect of natural biology that affects genetic diversity and genome evolution [1]. Dioecy is a sexual system where populations are made of distinct male and female individuals [2]. An estimated $6 \%$ of angiosperm species have

\footnotetext{
*Correspondence: nramadoss@sdsu.edu

${ }^{1}$ Department of Biology, San Diego State University, San Diego, USA Full list of author information is available at the end of the article
}

evolved separate sexes in a dioecious system, and dioecy has evolved at least 871 times independently in 175 families [3, 4]. Dioecy is also reported to have evolved from hermaphroditic flowers through the accumulation of mutations that drive male sterility in pistillate flowers and female sterility in staminate flowers [3]. Despite heavily depending on pollinators for a successful fertilization [5] and having fewer individuals that can produce seeds compared to the hermaphroditic populations, dioecious angiosperms are present in exclusively species 
rich dioecious clades, thereby negating any negative consequences [4]. Studies on unisexual flower development have shown that the developmental processes are not consistent among species and unisexual flower development is not well studied.

In diecious species, two types of developmental regulations are involved in producing unisexual flowers [6]. Type I involves carpel/stamen abortion after all the organs have been specified by the flower, but one sexual organ remains functional (Mitchell and Diggle [6]). This leads to unisexual flowers that carry vestigial organs of the other sex [7]. Type II involves the arrest of one sexual organ at a very early stage which leads to unisexual flowers by inception [6]. Programmed Cell Death (PCD) has been proposed as a principal force for driving the development of unisexuality in angiosperms through Type I $[8,9,10]$. However, the abortion of the male and female organs can occur in different stages and tissues $[11,12,13,14,15]$ and it is species dependent.

As abortion of one of the sexual whorls occurs late during the development of Type I flowers, non-functional sexual organs remain vestigial and unisexuality can be overlooked leading to the ambiguous description of the sexual systems. Thus, to describe the breeding system precisely, detailed morphological and developmental analyses or experimental crosses are necessary $[16,17]$. For example, some species have been originally considered as gynodioecious or androdioecious, but a closer look at their hermaphroditic flowers has shown they are functionally dioecious. For example, Spachea membranacea Cuatrec. (Malpighiaceae) and Withania aristata (Aiton) Pauquy (Solanaceae) were observed to have individuals with either hermaphroditic flowers or pistillate flowers, but crossing and anatomical experiments revealed that the hermaphroditic individuals were functioning as males, thus describing their sexual system as functionally dioecious $[18,19]$. A member of the Caryophyllaceae, Honckenya peploides (1.) Ehrh. var. major (Hook.) Abrams, was initially identified as androdioecious based on morphological studies and then proved to be functionally dioecious based on manual outcrosses performed over a consistent two year study period [20]. Thus, it is of importance to determine the sexual system of plants based on functional studies as their reproductive systems are often not accurately represented by superficial observations of the floral morphology $[21,18]$.

The family Cactaceae has about $\sim 2000$ species [22]. Most of them are hermaphroditic; although 23 species have Type I unisexual flowers in either dioecious, gynodioecious, or trioecious sexual systems ([23] and references therein). Within the cactus family, the description of the sexual systems has been ambiguous and imprecise, which is attributed mostly to anecdotal observation rather than detailed morphological analysis or experimental confirmation of the system [16]. Recent studies in the Cactaceae have advanced our understanding of the cellular mechanisms by which hermaphrodite flowers become unisexual, as well as their spatial and temporal patterns $[13,24]$. In most cacti specimens, pistillate flowers underwent degradation before the completion of meiosis. For instance, in the genus Consolea, [25] showed that pistillate flowers underwent abortion early during the onset of meiosis leading to sterile anthers bearing no pollen grains. In Opuntia stenopetala Englem., the pistillate flowers undergo various cellular changes associated with PCD (vacuolization, DNA degradation, cytoplasm collapse) in the microsporangium and all cell layers prior to completion of meiosis [13]. Similarly, in four species of Echinocereus with pistillate flowers, the microspore mother cell development was arrested prior to meiosis with other cell layers collapsing later [24].

In Cactaceae, female sterility varies considerably between taxa [15]. In the functionally dioecious $O$. stenopetala, the ovule abortion in staminate flowers was initiated in early primordial stages [26], whereas in Consolea, the ovule degeneration was induced prior to anthesis and after the development of embryo sac [27]. In Echinocereus, the ovule abortion takes place after the zygote is formed (post-fertilization) [24]. The role of PCD in female sterility of Cactaceae is not clearly determined. One recent study in Opuntia robusta H.L. Wendl. ex Pfeiff. showed that placental arrest and ovule abortion in staminate flowers were regulated by PCD [15].

Plants that are dioecious can deviate from the 1:1 sex ratio, especially those restricted to small populations, thereby decreasing their viability $[28,29]$. Among them, male biased ratios are at least twice as frequent as the female biased ones [28]. These biases are attributed to the differences in reproductive costs, pollen or seed dispersal, sex chromosomes and/or differential rate of mortality [28]. In Cactaceae, subdioecious populations of Consolea spinosissima (Mill.) Lem. [30] and Pachycereus pringlei (S. Watson) Britton \& Rose [31] as well as functionally dioecious populations of $O$. stenopetala have been reported to possess a male biased sex ratio.

Interestingly, several species of Cylindropuntia have been described as gynodioecious, with some individuals having perfect flowers and others having functionally female flowers $[32,33]$. These species are C. calmalliana (J.M. Coult.) F.M. Knuth, C. chuckwallensis M.A. Baker and M.A. Cloud-Hughes, C. molesta (Brandegee) F.M. Knuth, C. sanfelipensis (Rebman) Rebman, and C. wolfii (L. D. Benson) M.A. Baker. 


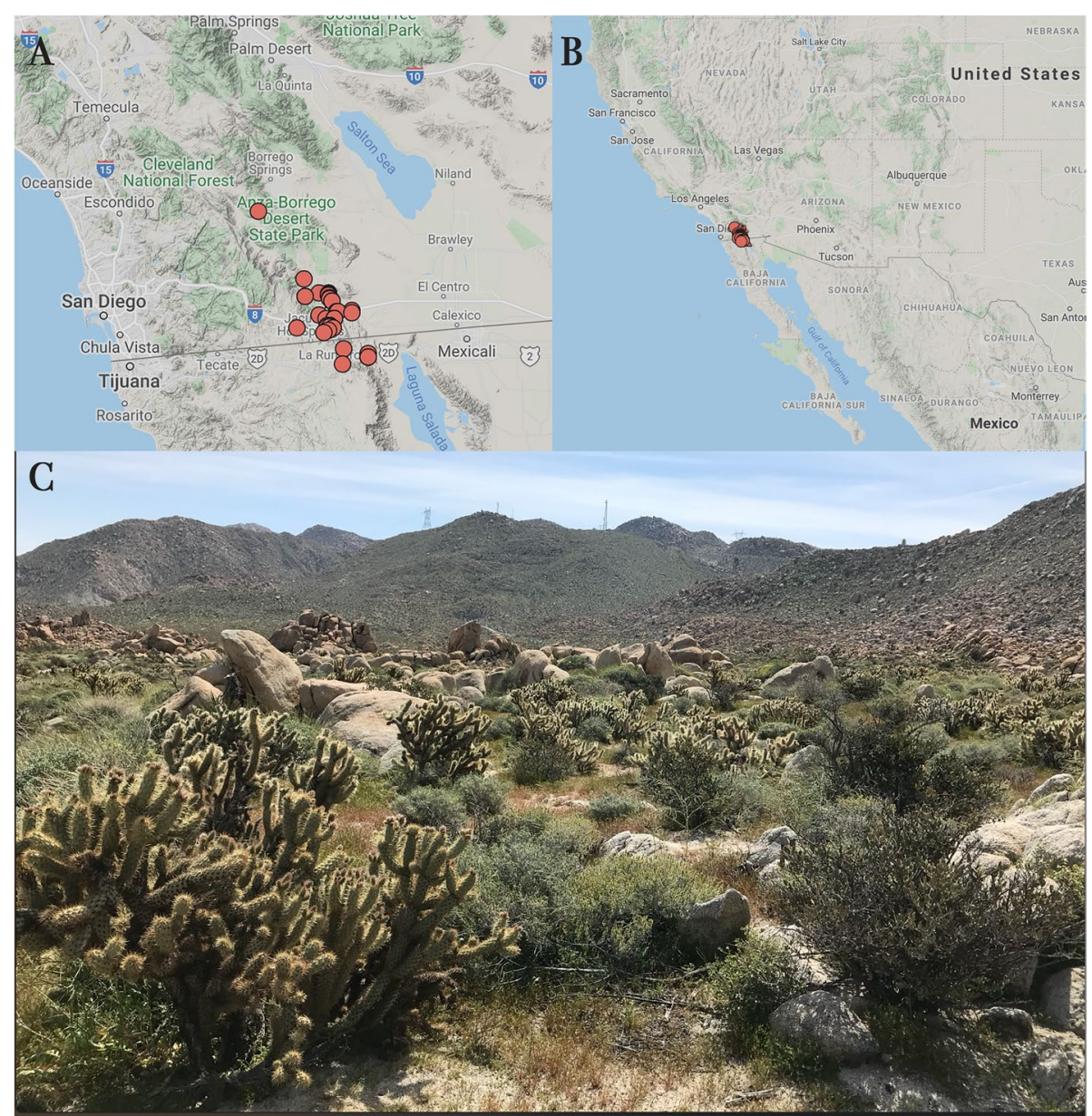

Fig. 1 Distribution of Cylindropuntia wolfii (A). This species has a narrow distribution in both California and Baja California, Mexico (B). Red points show the current distribution of C. wolfii. Occurrence data that included only precise points were extracted from SEINet Portal (www.swbiodiversity. orgL, misidentifications were excluded and the map was generated using Google imagery. (C) Natural occurrence of C. wolfii in Mountain Springs, Imperial County, California. Figures A and B were obtained from SEINet Portal and were collated with figure C in Adobe Photoshop

In our study, we focus on Cylindropuntia wolfii, which occurs within a very restricted range in extreme southern California, USA and extreme northern Baja California, Mexico (Fig. 1). This species has been described as gynodioecious based on field and herbarium specimen observations [32], but little is known about its reproductive biology. The putative female individuals were assumed because the anthers looked shriveled and no pollen was present. Type I flowers are easily misidentified by superficial observations, therefore, histological studies and experiments (e.g., manual crosses) are needed in order to accurately describe the sexual system in $C$. wolfii. Our goals are to determine the sexual system of $C$. wolfii and to describe the developmental processes contributing to the formation of unisexual flowers. We used a variety of histological observations, experimental crosses, and pollen viability tests.

\section{Results}

Based on histological examinations and cross-pollination experiments, we determined that $C$. wolfii is not gynodioecious as previously reported, but is instead functionally dioecious with bisexual flowers aborting one sex during the development process. Thus, the previously identified hermaphrodites are hereafter referred to as functional males or staminate flowers.

\section{Anther development Staminate flowers}

Staminate flowers develop a typical tetralocular anther with an anther wall composed of four single cell layers surrounding the Microspore Mother Cells (MiMCs). The wall is formed by the epidermis, endothecium, middle layer and tapetum (Fig. 2 A). Meiosis of the MiMCs results in four microspores, at this point the middle layer 


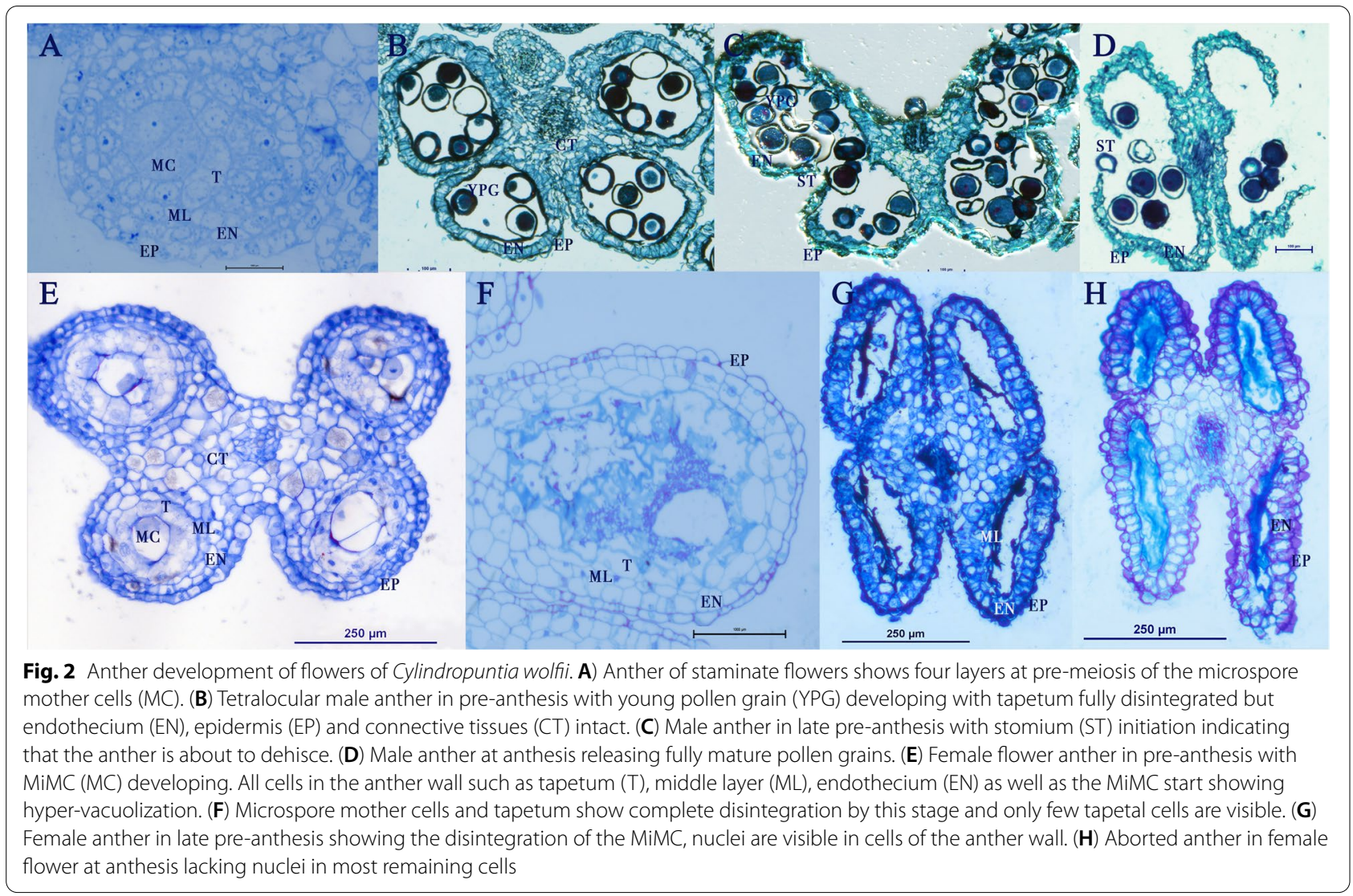

has already disappeared and the tapetum disintegrates which contributes to the pollen nutrition and wall ornamentation of the intermediate pollen grain (Fig. 2B). The epidermal cell begins to change into a conical shape. In late pre-anthesis, the anthers become bilocular with the disintegration of the connective tissues that form the septum of the microsporangia, and a stomium forms (Fig. 2 C). During anthesis, the last layer consists of endothecium and epidermis in conical shape. The wall dehydrates, and eventually dehisces (Fig. 2D) to reveal visible pollen (Fig. $3 \mathrm{~A}$ and $\mathrm{C}$ ).

\section{Pistillate flowers}

Anther development of pistillate flowers is interrupted after the formation of the MiMCs and does not undergo meiosis. At this stage, the MiMCs and the cells of the anther wall are highly vacuolated specially the tapetum (Fig. 2E). The MiMCs and the tapetum completely disintegrate, while the middle layer is atypically retained compared with the staminate flowers (Fig. 2 F). This is followed by the hypervacualization of the epidermis and the endothecium cells and the disintegration of their nuclei (Fig. $2 \mathrm{~F}, 2 \mathrm{G}$ ). In pistillate flowers, the anthers at anthesis do not dehisce. The septum that separates the two microsporangia in each thecae remains visible (Fig. $2 \mathrm{H}$ ), whereas it disintegrates in the male counterpart (Fig. 2 C). The anther development halts, no pollen is formed, and no dehiscence occurs. Therefore, no pollen is readily visible on the anthers of pistillate flowers (Fig. 3B and D).

\section{Ovule development Staminate flowers}

In staminate flowers, differentiation of the ovule primordia is similar to that of the pistillate flower until the formation of the megagametophyte. The ovule primordia develop the integuments, the funicle, and Megaspore Mother Cells (MeMC) (Fig. $4 \mathrm{~A}$ ). During the megagametogenesis, the young circinotropous ovule degenerates. The degeneration starts on the megagametophyte and extends to the nucelle (Fig. 4B). The funicle exhibited some signs of disruption but it is not known if that is a direct disintegration, or an artifact due to the lack of internal support of the ovule during the sectioning. At anthesis, the ovule is completely disintegrated, cellular debris can be observed along with tannins in the integuments and vascular system in the debris of the funicle (Fig. $4 \mathrm{C}$ ). Although staminate flowers' ovaries 

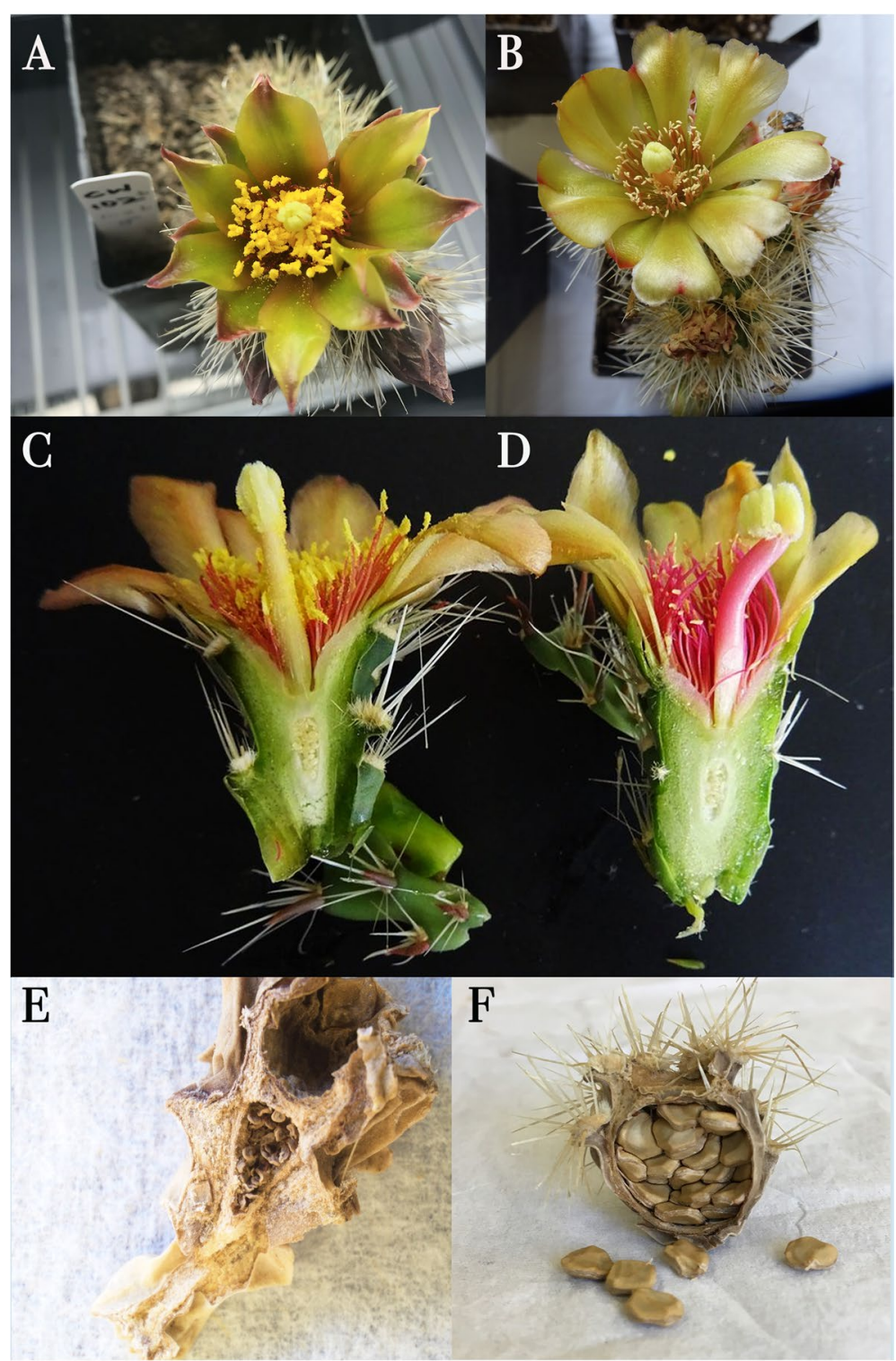

Fig. 3 (A) Cylindropuntia wolfii staminate flower (left) and pistillate flower (right). (B) Lateral cross-section of staminate flower (left) and pistillate flower (right). Fruits collected from a staminate plant $(\mathbf{C})$ and pistillate plant (D). Fruits collected from male $(\mathbf{E})$ and female plants $(\mathbf{F})$. The figures are our own, collated by Adobe Photoshop

carry ovules early in development, (Fig. 3 C) they are nonfunctional.

\section{Pistillate flowers}

In pistillate flowers, the primordial ovule developed starting with wrapping itself around by the long funicle, forming the integuments and the MeMCs (Fig. 4D). The pre-anthesis ovule has a curved nucelle, the MeMCs divides into 7 cells to form the megagametophyte. At this stage the development of the integuments is completed with the internal integument defining the micropyle (Fig. 4E). Tannin deposits in the integument are visible during megagametogenesis (Fig. 4E). At anthesis, the fully mature ovule is campylo-circinotropous. The megagametophyte is well developed and surrounded by the nucelle. The chalazal region is formed by the conjunction of the funicle and the integuments which have tannin deposits (Fig. 4 F). The embryonic sac develops seven cells - three antipodal cells are ephemeral and only four cells are found at maturity including the central cell, synergids and the egg at the micropylar end (Fig. 5). 


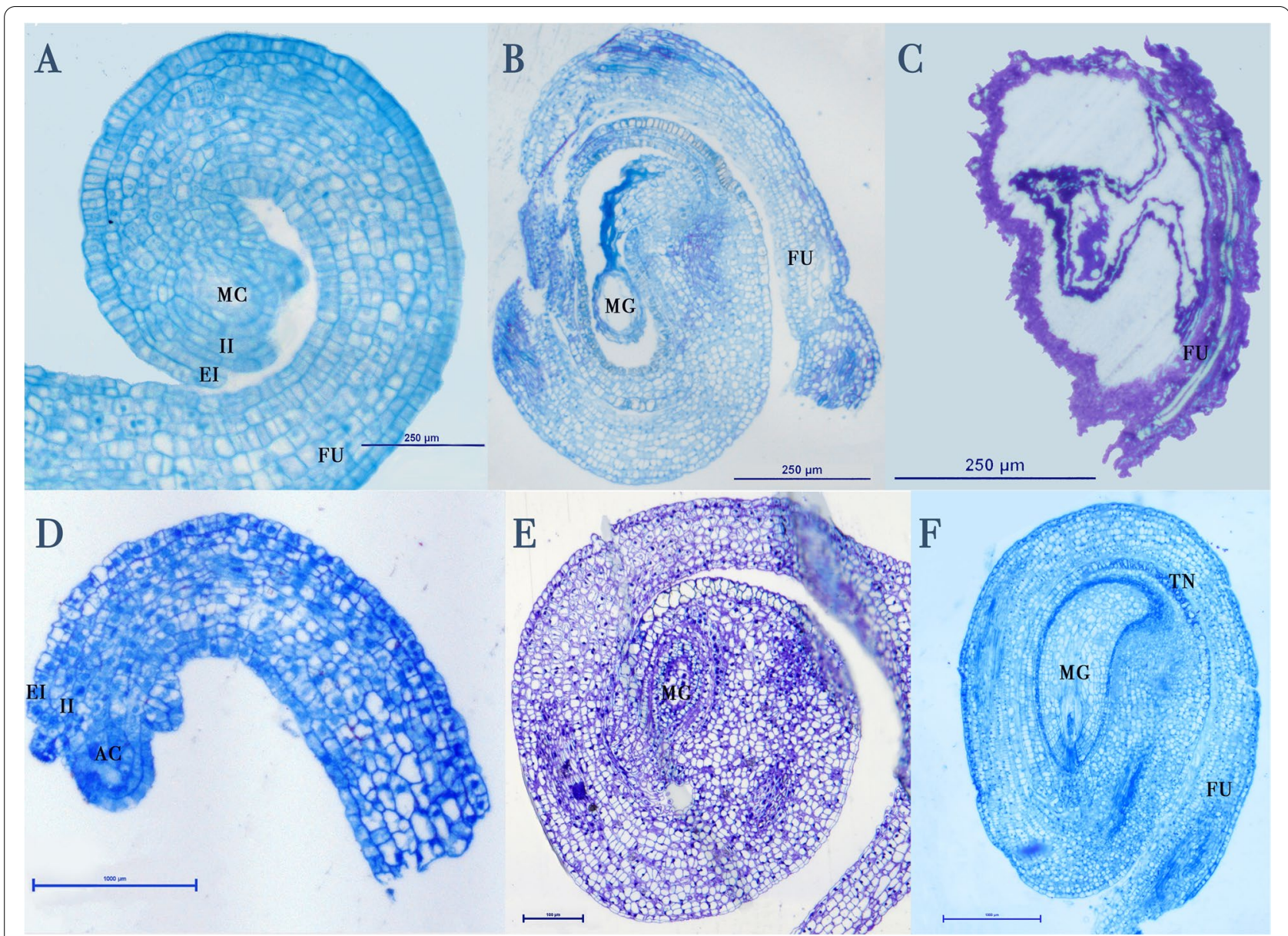

Fig. 4 Ovule development of flowers of Cylindropuntia wolfii. (A) Ovule in male flower at pre-anthesis, with long funicle (FU) and integuments (external (El) and internal (II)) developing with a Megaspore Mother Cell (MC). (B) Ovule of male flower in late pre-anthesis showing the collapse of the megagametophyte (MG). (C) Aborted ovule in male flower completely collapses in male flowers, at maturity only cellular debris are observed. (D) Ovule of female flower in early pre-anthesis, with a long funicle (FU) and integuments (external (EI) and internal (II)) developing with an archesporial cell (AC). (E) Ovule of female flower in early pre-anthesis showing the formation of the megagametophyte (MG). (F) Fully mature ovule of female flower in early pre-anthesis showing well developed megagametophyte and tannin (TN) deposits

\section{Pollen-stigma interaction}

To test the viability of the pollen and the receptivity of the stigma and style, the aniline blue dye was used to stain the callose in pollen tubes, enabling clear visualization of the germinated pollen in experimental crosses (Fig. 6). The germinated pollen tubes were observed in male $\times$ male selfed crosses (Fig. $6 \mathrm{~A}, \mathrm{~B}$ ) and female $\times$ male crosses (Fig. $6 \mathrm{C}, \mathrm{D}$ ). This germination of pollen in stigmas (Fig. 6 A, C) and style (Fig. 6B and D) of pistillate and staminate flowers indicates that the stigma and style of pistillate and staminate flowers are both functionally receptive. As pistillate flowers did not contain any pollen, there were no pollen tubes observed between male $\mathrm{x}$ female crosses and female $\mathrm{x}$ female selfed crosses.
Fruit development and seed set from natural and artificial crosses

To further examine which sex contributes to fruit and seed formation, field observations and experimental crosses were carried out. The fruits of $C$. wolfii become dry at maturity. Functionally female individuals were the only ones that formed mature fruits. Functionally male plants aborted the ovules, but ovaries were retained and dried (Fig. 3 C). Thus, the fruits of female individuals are larger than male aborted fruits (Fig. 7 A). However, many fruits were also aborted in functionally female plants, and some produced a few mature seeds with most ovules aborted, flattened, and located against the wall of the ovary (Fig. 7B). In contrast, no mature seeds were produced in functionally male individuals, (Fig. 7 C). Some 


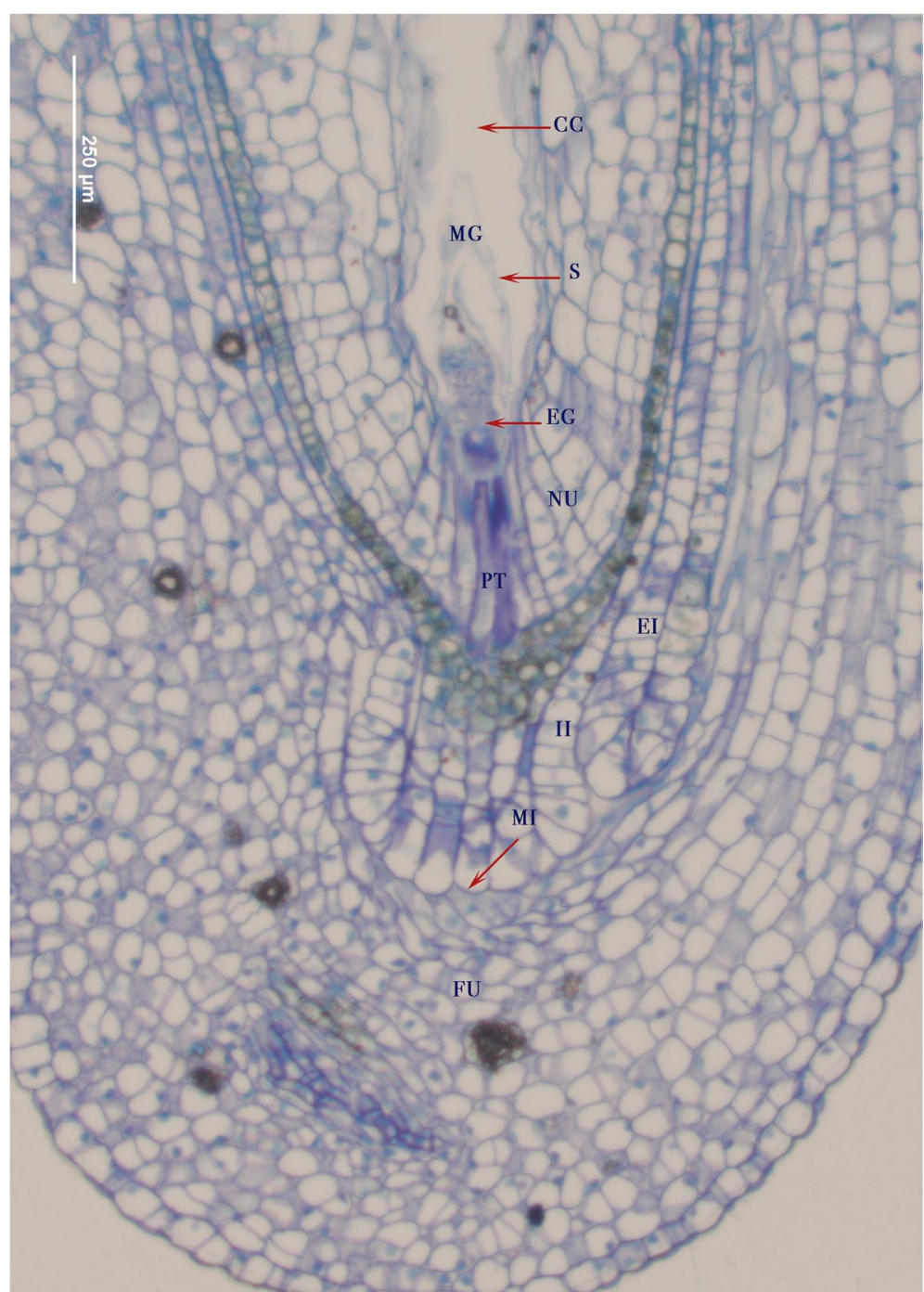

Fig. 5 Fertilization of the egg (EG) by pollen tube (PT) in megagametophyte (MG) of ovules of female flowers. The pollen tube enters through the micropyle (MI). The megagametophyte is surrounded by nucelle (NU), internal integument (II) and external integument (EI), which in turn is surrounded by the funicle (FU). Four cells are found at maturity including the central cell (CC), two synergids (S, only one visible) and the egg (EG)

mature seeds of functionally female individuals lacked embryos (Fig. 7D), but most developed mature embryos (Fig. 7E F). Since aborted ovules were visible under the microscope in both female and male fruits, we were able to estimate the seed set in both sexes in manual and natural crosses.

Using the controlled crossing experiment, we confirmed the ovule viability by formation of seeds. Fruits were collected when they appeared dry, plump, and brown (Fig. 7 A). The fruit set of males was 0 in all types of crosses and for females the values are as follows - (1) natural controls had a fruit set of 0.14 ; (2) outcross - 0.61 ; (3) selfing - 0 and (4) negative controls had 0.05 (Fig. 8A). From the collected fruits, we calculated the average seed set for each type of cross (Fig. 8B). The seed set values of females acting as pollen receptors were as follows: (1) natural controls had a seed set of 0.05; (2) outcross had a seed set of 0.25 ; (3) selfing had a seed set of 0 and (4) negative controls had a seed set of 0.01. Male individuals acting as pollen receptors had a seed set of 0 in every cross type. Our data showed that the staminate flowers produced no fruits or seeds in any type of crosses which denotes that even though they superficially appear to have a functional stigma and style, their ovules were not viable. On the other hand, we observed pistillate flowers to produce fruits and seeds in outcrosses, natural crosses and also in a single negative control individual. Overall, our results suggest that the pistillate flowers have viable 


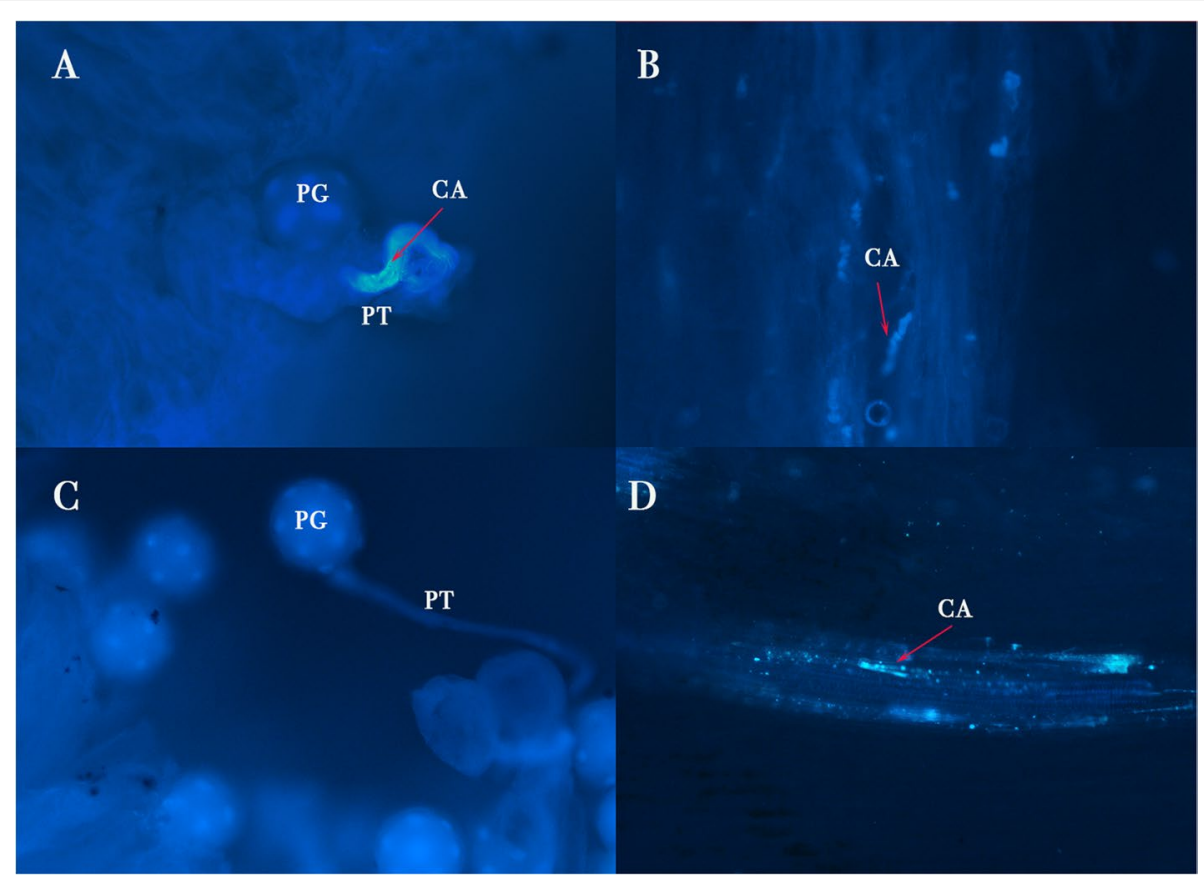

Fig. 6 Cylindropuntia wolfii pollen tube (PT) development from pollen grain (PG) on stigma and style of flowers used for the crosses (A, B) male $x$ male (selfing) male $x$ female $(\mathbf{C}, \mathbf{D})$. The callose $(C A)$ in the pollen tube fluoresces as a result of staining by aniline blue. Other crosses were not possible as females do not form pollen. Magnification:10X

ovules. Both sexual morphs subjected to selfing did not produce any seeds. This further supports that the sexual system of $C$. wolfii is functionally dioecious.

Our analysis shows that in general, the seed set of $C$. wolfii is low, 0.25 for outcrosses and 0.05 for natural crosses. This difference in seed set between natural and outcrosses is significantly different $(t=3.2568, \mathrm{df}=50$, $\mathrm{p}$-value $=0.002027$.

\section{Sex ratio}

Once we determined the sexual system, we estimated the sexual ratio in this species. A total of 137 plants were surveyed in the Mountain Springs area, 42 were identified as female individuals (31\%) and 95 were identified as males (69\%). The sex ratio of male: female was calculated to be 42:95, therefore there are approximately 2 males for every female in the sampled population. The male biased sex ratio is significant with $\mathrm{P}<0.0001, \mathrm{df}=1$.

\section{Discussion}

Given the recent evolution and wide polymorphism in sexual systems, Cactaceae is considered an ideal family to study sexual systems in plants [15]. Using histological observations, pollen viability tests, and controlled experimental crosses, we identified the sexual system of the rare cactus, Cylindropuntia wolfii, as functionally dioecious and not gynodioecious (individuals with hermaphroditic flowers and individuals with pistillate flowers) as previously described [32]. This species has a Type I flower, with functionally female individuals retaining aborted anthers and functionally males retaining aborted ovules. In the staminate flowers of $C$. wolfii the differentiation of the ovule primordia is similar to that of the pistillate flower until the formation of the megagametophyte. During megagametogenesis the young circinotropous ovule degenerates starting on the megagametophyte and extending to the nucelle. At anthesis, the ovule is completely aborted, but it is retained. The retention of the ovules on staminate flowers during anthesis, makes it difficult to identify whether they are aborted, reinforcing the idea that histological analyses are needed to accurately characterize the sexual system. The female sterility pattern exhibited in Cylindropuntia wolfii is similar to the one presented in Consolea spinosissima in which the ovules abort just before anthesis and start with the disintegration of nucelle proceeding to a complete breakdown of the ovule (Strittmatter et al. [30]). In comparison, in both O. robusta and O. stenopetala female sterility happens much earlier suppressing the ovule in its primordial stage [26, [15]. On the other hand, in Echinocereus the ovule abortion takes place only after the zygote is formed (post-fertlization) [24], requiring careful observation to determine the sexual system. These observations imply that the cellular mechanisms or pathways behind ovule 


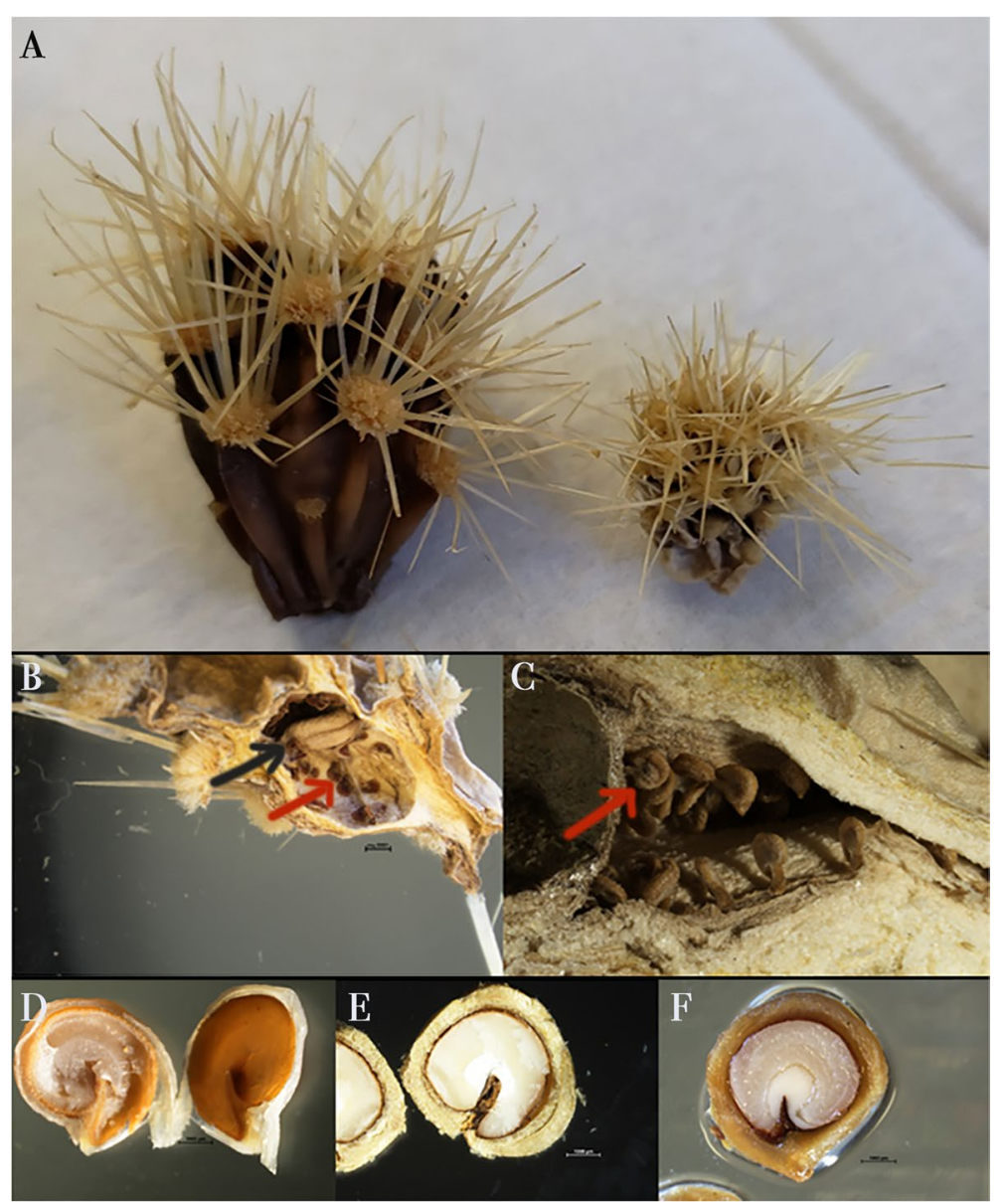

Fig. 7 Cylindropuntia wolfi fruit and seed development. A) Fruits of female (left) and male (right) individuals. Aborted ovules are found in fruits of both female (B) and male (C) individuals (red arrows), however, fruits of female individuals also form some mature seeds (black arrow). D-F) Mature seeds from fruits of female individuals showing the thick funicular coat. D) Seed with abnormal development that lacks the white solid embryo as shown in E-F. The latter shows a mature seed with endosperm consumed by the fully developed embryo and remaining perisperm (arrow). The figures are our own, collated by Adobe Photoshop

abortion in C. wolfii might be different from that of other species in the Cactaceae.

From our histological data, it was revealed that the androecium development in pistillate flowers was interrupted in pre-anthesis with complete degradation of the tapetum and MiMCs by late pre-anthesis. The early degradation of the tapetum is known to affect the nutrient supply to developing microspores by causing variations in callose metabolism and other tapetal enzymes critical for normal development $[34,35,36]$. This pattern of tapetal disintegration is common in dioecious species of Cactaceae studied thus far although the temporal patterns might differ [15]. The mechanism behind tapetal disintegration in most of the cacti species - Opuntia robusta [15], O. stenopetala [13], and in the dioecious species of Echinocereus [24] is reported to be PCD. Moreover, tapetal disintegration by itself is a hallmark of $\mathrm{PCD}$ because mutations in male developmental genes lead to premature PCD or retarded PCD ultimately damaging the tapetum [22]. In conclusion, tapetal disintegration to attain male sterility might be a conserved trait of the Cactaceae.

Similar to C. wolfi, O. robusta and six species of Consolea have staminate flowers that appear to be hermaphroditic having a functional looking stigma and style. Our pollen germination tests showed that the stigma of staminate flowers in $C$. wolfii is functional which is also true for O. robusta and Consolea [37, 27, 15]. This suggests that there are no genetic or developmental barriers in the earlier stages of pollen recognition or pollen germination in $C$. wolfii. In contrast, the staminate flowers of O. stenopetala are devoid of stigmatic tissues suggesting a strict self-incompatibility mechanism [26]. Thus, the degree of degradation in stigma and style differs among cactus 


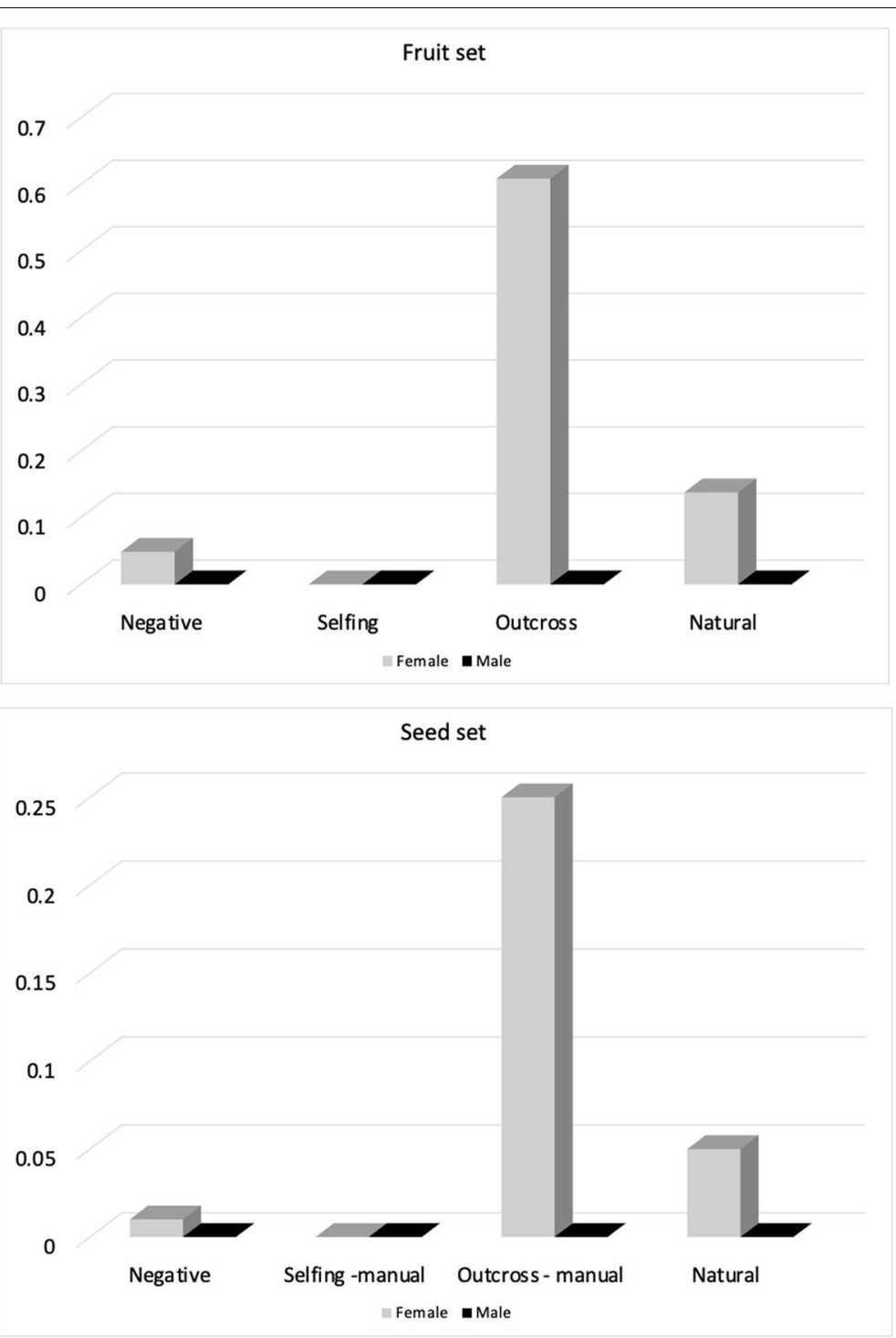

Fig. 8 Experimental crosses in Cylindropuntia wolfii. (A) Bar chart showing the average fruit set (Y axis) obtained from various controlled crosses (X axis) in functionally female (gray bars) and functionally male (black bars) individuals. (B) Bar chart showing the average seed set (Y axis) obtained from various controlled crosses in functionally female (gray bars) and functionally male (black bars) individuals

species. The ovule abortion is the main cause for female sterility in most species of Cactaceae although the timing and degree of abortion differs. Although in O. robusta, female sterility was regulated by PCD [15], it is unclear if this mechanism is conserved throughout the Cactaceae.

The controlled experimental crosses showed that functional males were not capable of producing seeds through any crosses, further confirming that their ovules are nonfunctional. The pistillate flowers produced seeds in outcrosses, natural crosses, and also in one functional female used as a negative control (bagged flowers). The seeds found in the female negative control could result from an improperly bagged flower that allowed insect visitation or a sign of apomixis (i.e., adventive embryony) - which is the formation of seeds without pollination and this kind of reproduction has been reported previously in a variety of Opuntia species [38] and in C. fulgida (Engelm.) F.M.Knuth [39]. Overall, our results suggest that the pistillate flowers have viable ovules but staminate flowers abort the ovules and are unable to produce seeds. This confirms that the sexual system of $C$. wolfii is functionally dioecious.

The seed set data from controlled crosses showed that, in general, the seed set of $C$. wolfii is low, and has 
been reported to produce generally abortive seeds [40], but very little is known about its reproductive biology. A similarly low value of seed set (avg: 37 seeds/ 158 ovules $=0.23$ seed set) has been observed in $O$. microdasys (Lehm.) Pfeiff. where sexual recruitment by seeds is rare. Moreover, the seed set of $C$. wolfii was significantly lower in natural crosses as compared to manual crosses. This suggests that, in 2019, natural pollination may not be as effective as manual pollination in C. wolfii, possibly because of a low number of pollinators. Ecological studies are needed to ascertain the factors causing the reduced seed set in our system. About $40 \%$ of our outcrossed fruits failed to produce seeds. Some species of Cactaceae are narrowly distributed and dioecy could evolve to avoid the negative effects of inbreeding depression [41]. If dioecy prevents inbreeding depression through avoidance of selfing then why is the seed set of $C$. wolfii low? The low seed set suggests $C$. wolfii is struggling for sexual reproduction and the lack of easily detached segments suggests it does not use clonal propagation as its main way of reproduction. These combined might explain its restricted distribution. This, in turn, might lead to low levels of genetic diversity and high levels of inbreeding $[42,43]$ reducing the adaptive potential, and population genetic studies are necessary to address this concern and develop conservation strategies.

The sex ratio of the Cylindropuntia wolfii population in Mountain Springs (Imperial County) was significantly male-biased. Among dioecious species, a male-biased sex ratio is twice as common as the female-biased one [28]. A high female reproductive investment may be the cause of the male-biased sex ratio [44]. In order to precisely identify the causes of a male-biased ratio in C. wolfii, we need to evaluate the stage of lifecycle in which the bias is established and factors that contribute to sex ratio differences such as life history traits (survival, growth, flowering, clonality, etc.) and phylogenetic relationships [28]. One of the consequences of a skewed sex ratio is a lower effective population size that can lead to bottleneck effects. Theory predicts that male biased populations have a lower inbreeding than the female biased populations [45]. Experimental studies would be of interest to test this hypothesis and ascertain if that is why most dioecious plants are male biased.

The evolution of sexual separation and its association to polyploidy has been known for a long time [46], but it is uncertain whether it is a cause, a consequence or both. This relation is also seen in many species of Cactaceae. For example, Pachycereus pringlei, O. robusta, Consolea species and five species of Echinocereus have a sexual system with unisexual flowers (e.g., trioecious, gynodioecious or dioecious) and have a level of polyploidy either as tetraploid, hexaploid or octaploid [47, 48, 49, 50, 51].
This pattern is consistent in the genus Cylindropuntia in which polyploid species are either gynodioecious, e.g., C. chuckwallensis, C. sanfelipensis, C. calmalliana, and C. molesta (see [52]) or functionally dioecious such as in C. wolfii. Exceptions to this rule include the subdioecious and diploid O. stenopetala and O. grandis Pfeiff. [52], the apparently hermaphroditic and the triploid C. arbuscula (Griffiths) F.M.Knuth, which seems to propagate mostly clonally $[52,53]$, other hermaphroditic species such as C. bigelovii (Engelmann) F.M.Knuth is mostly triploid and rarely diploid, C. prolifera (Engelmann) F.M.Knuth is triploid and C. cholla (F.A.C.Weber) F.M.Knuth is mostly diploid and rarely tetraploid [54]. However, C. wolfii was previously described as gynodioecious but in this study we have shown that it has a functionally dioecious system. Therefore, a detailed study is warranted for the other polyploid species of Cylindropuntia whose sexual systems are described based on superficial observations (e.g., C. arbuscula, C. calmalliana, C. chuckwallensis, C. molesta, C. sanfelipensis).

\section{Conclusions}

Our study is the first investigating the developmental mechanism of unisexuality in the genus Cylindropuntia. Through controlled cross experiments, histological analysis, and pollen viability tests, we identified the sexual system of $C$. wolfii, a rare and endemic cactus of the Sonoran Desert, as functionally dioecious rather than gynodioecious as previously described. Furthermore, we described the developmental process of unisexual flowers showing that the ovule abortion in staminate flowers and pollen abortion in pistillate flowers were asynchronous, occurring during and before anthesis respectively. Interestingly, the stigma and style of the functional staminate flowers remains viable suggesting this species controls female abortion at the ovule level only. Even though the pistillate flowers are functional there was a low seed set in both natural and manual crosses of $C$. wolfii suggesting that this species might be struggling to reproduce sexually which might explain its restricted distribution. The reduced sexual reproduction of this species and its small distribution might result in low genetic diversity and it should be further investigated. Field and genetic studies will offer insights into the consequences of dioecy in this species.

\section{Methods \\ Plant Material}

Cylindropuntia wolfii is listed on the Inventory of Rare and Endangered Plants by the California Native Plant Society, rare plant program [55] at CA Rare Plant Rank 4.3 due to its limited distribution, but the populations are not very threatened. It is narrowly distributed in the 
Sonoran Desert of southern California and Baja California [56] (Fig. 1). It is a hexaploid succulent shrub that is densely branched with stout cylindrical stems having terminal branchlets that are not easily detached. The stems have dense spination and oblong to obovate tubercles bearing the spines [57]. The flowers have a variable tepal color on different individuals ranging from yellow-bronze to red with a pink to red style and stamens with yellow to red filaments. The fruits are dry at maturity, densely spined to bur-like, and most often do not contain seeds.

Dr. Rebman undertook the formal identification of C. wolfi samples. We have permission to collect samples from the Schultz family at the privately owned Desert View Tower (Imperial County, CA) (32.6592 N, $116.0999 \mathrm{~W})$. A permit from the Bureau of Land Management (CAD07-F-2018.00000001) issued to Dr. Jon Rebman for scientific and educational purposes was used to collect material at Mountain Springs (Imperial County, CA) $(32.674509 \mathrm{~N}, 116.098834 \mathrm{~W})$. We tagged 47 individuals, 27 putative hermaphrodites (flowers with developed anthers which released pollen at anthesis and a normal pistil, Fig. $3 \mathrm{~A}, \mathrm{C}$ ) and 20 morphologically female (with reduced anthers and a lack of pollen at anthesis, Fig. 3B and D). The flowers were collected at different development stages, ranging from early pre-anthesis to late postanthesis based on the presumed sex of the parent plants via observed flower morphology. A voucher specimen has been deposited in the San Diego State University Herbarium (CCH1 specimen number SDSU22474).

\section{Histological methods}

To analyze the morphological development, flowers and buds from $C$. wolfi $i$ were collected at different stages for separating and sectioning the anthers and ovules. Some flowers were placed in plastic vials containing formalinacetic acid-alcohol (FAA). These samples for sectioning were dehydrated in an ascending series of ethanol and transferred to xylene substitute and embedded in paraffin. Blocks were sectioned at $10 \mu \mathrm{m}$ and stained with safranin and fast-green [58]. The samples were fixed in $4 \%$ paraformaldehyde in $1 \times$ phosphate-buffered saline (PBS). This was followed by dehydration using ethanol in increasing concentrations. Fixed samples were embedded through LR White Resin medium grade (Electron Microscopy Sciences, Fort Washington, PA, USA). LRWhite-embedded samples were sectioned at 1-3 $\mu \mathrm{m}$ using an ultramicrotome (Reichert- Jung Ultracut E) and stained with toluidine blue solution (1\% toluidine blue and $1 \%$ sodium borate in distilled water) using [59] procedure in Polychrome Stains for High Resolution Light Microscopy. Stained samples were mounted with Kleermount ${ }^{\circledR}$ solution. The mounted samples were viewed under a compound microscope (Nikon Microphot-FX) at different objectives.

\section{In-vivo pollen germination test}

In order to test for pollen viability and stigma receptivity, a pollen germination test was performed. Manual crossing was done between different sexes at the time when the flowers were fully open. The flowers were collected approximately $48 \mathrm{~h}$ after the manual crossing and the pistils were removed. The pistils were prepared for analysis by following the procedure mentioned by [60] with a few modifications. The pistils were fixated in 3:1 ethanol: acetic acid solution for $24 \mathrm{~h}$. After fixation, the samples were cleared by immersion in $1 \mathrm{M}$ sodium sulphite for $25 \mathrm{~min}$. This was followed by immersion in $1 \%$ aniline blue overnight. The pistils were then sectioned longitudinally and flattened on a clean glass slide. Glycerol at $50 \%$ concentration was used as the mounting medium. The samples were viewed with a compound microscope (Nikon Microphot-FX) at 10X objective under UV light.

\section{Crosses}

To further test for ovule and pollen viability, controlled crosses were conducted between the putative hermaphroditic and female individuals in the field. A total of 130 crosses were performed. Plants were surveyed in early March 2018 and 2019 for floral buds, and in April 2018 and 2019 pollination tests were performed. Crosses were divided into 4 types: (1) natural controls - open pollinated flowers, (2) outcross - pollen from hermaphroditic flowers was manually deposited on stigmata of pistillate flowers and anthers from pistillate flowers were rubbed on the stigmas of hermaphroditic flowers as pistillate flowers lack pollen, (3) selfing - manually pollinated self-crosses for hermaphroditic and pistillate flowers and (4) negative control - bagged flowers to prevent natural and artificial pollination. Each cross was noted with a colored tag and protected with fabric bags (ULINE, 2018). A monthly survey was conducted, and dry fruits were collected from August-September 2018 and August-September 2019. Ovule counts, developed seed counts, and terminated ovule counts were done using a Nikon SMZ25 stereoscopic microscope. The seed set was calculated as the ratio of developed seeds with respect to the total number of ovules. A value of 0 indicates that no seeds were formed or no ovules were fertilized and a value of 1 indicates that all the ovules were fertilized to form seeds. A Welch two sample $\mathrm{t}$-test was performed in the $\mathrm{R}$ program [61] to check if the seed set mean of outcrosses vs. natural crosses differed significantly between the pistillate flowers. The fruit set was calculated as the ratio of fruits with seeds with respect to the total number of flowers. 
A value of 0 indicates that no fruits were formed and a value of 1 indicates that all the flowers developed to fruits.

\section{Sex Ratio}

We surveyed the plants present in a $600 \mathrm{~m}$ transect in Mountain Springs, Imperial County, California. The sexes were identified through the presence/absence of dehiscent anthers releasing mature pollen at anthesis and in some flowers through the presence of ovules in flowers and confirmed by performing viability tests and cross sections in the lab as described above. The observed sex ratio was compared to the expected 1:1 sex ratio through chi square test in MS Excel using CHISQ.TEST function.

\section{Abbreviations}

PCD: Programmed Cell Death; MiMC: Microspore mother cell; MeMC: Megaspore mother cell.

\section{Acknowledgements}

This work is supported by the Hispanic-Serving Institutions Education Grants (HSI) Program [grant no. 2018-38422-28614/project accession no. 1016839] from the USDA National Institute of Food and Agriculture. The authors thank Hao Duong, Yan Li, Mikayla Krzmarzick, Kiley Silva, Alex McElwee-Adame, Kyle Gunther, Sandra Hysat, Alice Hossfeld, Ryan Buck and Nelly Rodriguez who kindly helped us in our field work and material processing; SDGE and the owners of the desert view tower, for providing access to the field sites.

\section{Authors' contributions}

LF-R and JR conceived the study; LF-R formulated the hypotheses, supervised the project and secured funding for this study; NR and AOB collected the data; NR performed pollen visualization experiment; $A O B, C P$ and SS processed samples; NR performed data analyses; NR and LF-R wrote the manuscript and $\mathrm{JR}$, and $\mathrm{AOB}$ provided comments. All authors read and approved the manuscript.

\section{Funding}

This work is supported by the Hispanic-Serving Institutions Education Grants (HSI) Program [grant no. 2018-38422-28614/project accession no. 1016839] from the USDA National Institute of Food and Agriculture. Their funds supported undergraduate research of Carlos Portillo and Amy Orduño-Baez, and fieldwork.

\section{Availability of data and materials}

Data sharing not applicable to this article as no datasets were generated or analyzed during the current study.

\section{Declarations}

Ethics approval and consent to participate

Not applicable.

\section{Consent for publication}

Not applicable.

\section{Competing interests}

The authors declare that they have no competing interests.

\section{Author details}

${ }^{1}$ Department of Biology, San Diego State University, San Diego, USA. ${ }^{2}$ University of Santa Cruz, San Diego, USA. ${ }^{3}$ Department of Botany, San Diego Natural History Museum, San Diego, USA.
Received: 28 August 2021 Accepted: 7 January 2022

Published online: 02 March 2022

\section{References}

1. Charlesworth D. Evolution of plant breeding systems. Curr Biol. 2006;16(17):R726-35.

2. Freeman DC, Harper KT, Ostler WK. Ecology of plant dioecy in the intermountain region of western North America and California. Oecologia. 1979:44(3):410-7.

3. Charlesworth D, Guttman DS. The evolution of dioecy and plant sex chromosome systems. Sex determination in plants. 1999; 25-49.

4. Renner SS. The relative and absolute frequencies of angiosperm sexual systems: dioecy, monoecy, gynodioecy, and an updated online database. American Journal of botany. 2014;101(10):1588-96.

5. Westergaard M. The mechanism of sex determination in dioecious flowering plants. Adv Genet. 1958;9:217-81.

6. Mitchell $\mathrm{CH}$, Diggle PK. The evolution of unisexual flowers: morphological and functional convergence results from diverse developmental transitions. Am J Bot. 2005;92:1068-76.

7. Sobral R, Silva HG, Morais-Cecílio L, Costa MM. The quest for molecular regulation underlying unisexual flower development. Frontiers in plant science. 2016:7:160.

8. Irish EE, Nelson T. Sex determination in monoecious and dioecious plants. Plant Cell. 1989:1(8):737

9. Lebel-Hardenack S, Grant SR. Genetics of sex determination in flowering plants. Trends Plant Sci. 1997;2(4):130-6.

10. Wu HM, Cheung AY. Programmed cell death in plant reproduction. Programmed Cell Death in Higher Plants. 2000; 23-37.

11. Caporali E, Spada A, Marziani G, Failla O, Scienza A. The arrest of development of abortive reproductive organs in the unisexual flower of Vitis vinifera ssp. sylvestris Sexual Plant Reproduction. 2003;15:291-300.

12. Coimbra S, Torrao L, Abreu I. Programmed cell death induces male sterility in Actinidia deliciosa female flowers. Plant Physiol Biochem. 2004:42:537-41.

13. Flores-Rentería L, Orozco-Arroyo G, Cruz-García F, García-Campusano F, Alfaro I, Vázquez-Santana S. Programmed cell death promotes male sterility in the functional dioecious Opuntia stenopetala (Cactaceae). Ann Bot. 2013;112(5):789-800

14. Caporali E, Testolin R, Pierce S, Spada A. Sex change in kiwifruit (Actinidia chinensis Planch.): a developmental framework for the bisexual to unisexual floral transition. Plant reproduction. 2019;32(3):323-30.

15. Hernández-Cruz R, Silva-Martínez J, García-Campusano F, Cruz-García F, Orozco-Arroyo G, Alfaro I, Vázquez-Santana S. Comparative development of staminate and pistillate flowers in the dioecious cactus Opuntia robusta. Plant Reproduction. 2019;32(3):257-73.

16. Hoffman MT. Functional dioecy in Echinocereus coccineus (Cactaceae): breeding system, sex ratios and geographic range of floral dimorphism. Am J Bot. 1992;79:1382-8.

17. Wang S, Jin CF, Li ZQ, Li Y, Xie Q. Breeding system and parental effect on fruit characters of Idesia polycarpa (Flacourtiaceae), a promising plant for biodiesel, in northwest China. Pak J Bot. 2017:49(5):1885-90.

18. Steiner KE. Functional dioecism in the Malpighiaceae: the breeding system of Spachea membranacea Cuatr. Am J Bot. 1985;72(10):1537-43.

19. Anderson GJ, Bernardello G, Opel MR, Santos-Guerra A, Anderson M. Reproductive biology of the dioecious Canary Islands endemic Withania aristata (Solanaceae). American Journal of Botany. 2006;93(9):1295-305.

20. Tsukui T, Sugawara T. Dioecy in Honckenya peploides var. major (Caryophyllaceae). The botanical magazine= Shokubutsu-gaku-zasshi. 1992; 105(4): 615-624

21. Lloyd DG. Sexual strategies in plants III. A quantitative method for describing the gender of plants. N Z J Bot. 1980;18(1):103-8.

22. Anderson EF, Brown R. The Cactus Family 776. Timber press. Portland; 2001

23. Sánchez D, Vázquez-Santana S. Embryology of Mammillaria dioica (Cactaceae) reveals a new male sterility phenotype. Flora. 2018;241:16-26.

24. Hernández-Cruz R, Barrón-Pacheco F, Sánchez D, Arias S, VázquezSantana S. Functional dioecy in Echinocereus: ontogenetic patterns, programmed cell death, and evolutionary significance. Int J Plant Sci. 2018;179(4):257-74 
25. Strittmatter LI, Negrón-Ortíz V, Hickey RJ. Comparative microsporangium development in male-fertile and male-sterile flowers of Consolea (Cactaceae): when and how does pollen abortion occur. Grana. 2006;45:81-100.

26. Orozco-Arroyo G, Vázquez-Santana S, Camacho A, Dubrovsky JG, CruzGarcía F. Inception of maleness: auxin contribution to flower masculinization in the dioecious cactus Opuntia stenopetala. Planta. 2012;236:225-38.

27. Strittmatter LI, Hickey RJ, Negrón-Ortiz V. Heterochrony and its role in sex determination of cryptically dioecious Consolea (Cactaceae) staminate flowers. Bot J Linn Soc. 2008;156:305-26.

28. Field DL, Pickup M, Barrett SC. Comparative analyses of sex-ratio variation in dioecious flowering plants. Evolution: International Journal of Organic Evolution. 2013;67(3):661-72.

29. Cuevas E, Pérez MA, Sevillano L. Population size, sex-ratio and sexual dimorphism in Fuchsia parviflora (Onagraceae) an endemic dioecious shrub. Botanical Sciences. 2017;95(3):401-8.

30. Strittmatter LI, Negrón-Ortiz V, Hickey RJ. Subdioecy in Consolea spinosissima (Cactaceae): breeding system and embryological studies. American Journal of Botany. 2002;89:1373-87.

31. Fleming TH, Maurice S, Hamrick JL. Geographic variation in the breeding system and the evolutionary stability of trioecy in Pachycereus pringlei (Cactaceae). Evol Ecol. 1998;12(3):279-89.

32. Rebman JP. A new cholla (Cactaceae) from Baja California. Haseltonia. 1998:6:17-21.

33. Rebman JP, Pinkava D. Opuntia cacti of North America- an overview Florida Entomologist. 2001;84:474-83.

34. Dong X, Hong Z, Sivaramakrishnan M, Mahfouz M, Verma DPS. Callose synthase (CalS5) is required for exine formation during microgametogenesis and for pollen viability in Arabidopsis. Plant J. 2005;42:315-28.

35. Xu J, Ding Z, Vizcay-Barrena G, Shi J, Liang W, Yuan Z, Werck-Reichhart $D$, et al. Aborted microspores: acts as a master regulator of pollen wall formation in Arabidopsis. Plant Cell. 2014;26(4):1544-56.

36. Zhang D, Lv X, Wang Y, Xun Z, Liu Z, Li F, Lu H. The Cysteine Protease CEP1 a key executor involved in tapetal programmed cell death, regulates pollen development in Arabidopsis. Plant Cell. 2014;26(7):2939-61.

37. Negrón-Ortiz V, Strittmatter LI. Embryology of floral dimorphism and gender system in Consolea corallicola (Cactaceae), a rare species of the Florida Keys. Haseltonia. 2004;10:16-25.

38. Griffith MP. Experimental hybridization of northern Chihuahuan Desert region Opuntia (Cactaceae). Aliso: A Journal of Systematic and Evolutionary Botany 2001; 20(1): 37-42.

39. Baker MA, Pinkava DJ. A cytological and morphometric analysis of a triploid apomict, Opuntia x kelvinensis (subgenus Cylindropuntia, Cactaceae). Brittonia. 1987; 39(3): 387-401.

40. Mayer MS, Gromova A, Hasenstab-Lehman K, Lippitt M, Barnett M, Rebman JP. Is Cylindropuntia x fosbergii (Cactaceae) a hybrid? Madroño. 2011;58(2):106-12.

41. Austerlitz F, Gleiser G, Teixeira S, Bernasconi G. The effects of inbreeding, genetic dissimilarity and phenotype on male reproductive success in a dioecious plant. Proceedings of the Royal Society B: Biological Sciences. 2012;279 (1726): 91-100

42. Silvertown J. The evolutionary maintenance of sexual reproduction: evidence from the ecological distribution of asexual reproduction in clonal plants. Int J Plant Sci. 2008;169(1):157-68.

43. Hamadeh B, Chalak L, d'Eeckenbrugge GC, Benoit L, Joly HI. Evolution of almond genetic diversity and farmer practices in Lebanon: impacts of the diffusion of a graft- propagated cultivar in a traditional system based on seed-propagation. BMC Plant Biol. 2018;18(1):155.

44. Charnov EL. The theory of sex allocation. Princeton: Princeton Univ. Press; 1982.

45. Sinclair JP, Emlen J, Freeman DC. Biased sex ratios in plants: theory and trends. The Botanical Review. 2012;78:63-86.

46. Stebbins GL. Chapter VIII. Polyploidy I. Occurrence and Nature of Polyploid Types. In: Variation and evolution in plants. Columbia University Press; 1950. pp. 298-341.

47. Ferguson DJ. Revision of the US members of the Echinocereus triglochidiatus group. Cactus Succulent Journal. 1989;61:217-24.

48. Rebman JP. The genus Echinocereus in Lower California, Mexico: taxonomy, rarity and reproductive biology. Cactus Succulent Journal. 2003:75:194-6.
49. Baker M. A new florally dimorphic hexaploid, Echinocereus yavapaiensis sp. nov. (section Triglochidiati, Cactaceae) from central Arizona. Plant Syst Evol. 2006:258:63-83.

50. Segura S, Scheinvar L, Olalde G, Leblanc O, Filardo S, Muratalla A, Gallegos C, Flores C. Genome sizes and ploidy levels in Mexican cactus pear species Opuntia (Tourn.) Mill. series Streptacanthae Britton et Rose, Leucotrichae DC. Heliabravoanae Scheinvar and Robustae Britton et Rose. Genet Resour Crop Evol. 2007;54(5):1033-41.

51. Majure LC, Puente R, Griffith MP, Judd WS, Soltis PS, Soltis DE. Phylogeny of Opuntia s.s. (Cactaceae): clade delineation, geographic origins, and reticulate evolution. American journal of botany. 2012; 99(5): 847-864.

52. Baker MA, Cloud-Hughes MA. Cylindropuntia chuckwallensis (Cactaceae), a new species from Riverside and Imperial counties. California Madroño. 2014:61:231-43.

53. Pinkava DJ, McLeod MG. Chromosome numbers in some cacti of western North America. Brittonia. 1971;23(2):171-6.

54. Baker MA, Rebman JP, Parfitt BD, Pinkava DJ, Zimmerman AD. Chromosome numbers in some cacti of Western North America-VIII. Haseltonia. 2009;15:117-34.

55. California Native Plant Society, Rare Plant Program. (1968 onward continuously updated) Inventory of rare and endangered plants of California (online edition, v8-03 0.39). Website http://www.rareplants.cnps.org [accessed 0803 2021].

56. Benson LD, Baker MA (2003 onward continuously updated) Calflora: Information on California plants for education, research and conservation, with data contributed by public and private institutions and individuals, including the Consortium of California Herbaria 2021. Berkeley: The Calflora Database. Website. https://www.calflora.org [accessed: 2703 2021].

57. Pinkava DJ, Parfitt BD, Baker MA, Worthington RD. Chromosome numbers in some cacti of western North America-VI, with nomenclatural changes. Madroño. 1992:39(2):98-113.

58. Ruiz SE. Plant Microtechnique and Microscopy. Oxford University Press; 1999.

59. Hoffmann EO, Flores TR, Coover J, Garrett HB. Polychrome stains for high resolution light microscopy. Laboratory Medicine. 1983;14(12):779-81.

60. Livia DJ, Jose RF, Alfredo AC, Carlos AD, Fernanda VD. Use of aniline blue stain to observing pollen tubes development in different Manihot Mill. species. Afr J Agric Res. 2015;10(15):1805-9.

61. Core Team R R: A language and environment for statistical computing. $R$ Foundation for Statistical Computing, Vienna, Austria. 2017. URL https:// www.R-project.org/.

\section{Publisher's Note}

Springer Nature remains neutral with regard to jurisdictional claims in published maps and institutional affiliations.

Ready to submit your research? Choose BMC and benefit from

- fast, convenient online submission

- thorough peer review by experienced researchers in your field

- rapid publication on acceptance

- support for research data, including large and complex data types

- gold Open Access which fosters wider collaboration and increased citations

- maximum visibility for your research: over 100M website views per year

At BMC, research is always in progress.

Learn more biomedcentral.com/submissions 